\title{
Analysis of Blood Serum and Gallstone Lipids Composition of Gallstone Patients
}

\author{
Mohamed A. H. Jasim \\ Department of Chemistry / College of Education \\ Mosul University
}

Received

14 / 06 / 2009
Accepted

$06 / 10 / 2009$

\section{الخلاصة}

صمدت هذه الدراسة لمقارنة المكونات الدهنية وتركيب أحماضها الدهنية في مصل الدم وحصى الدهى

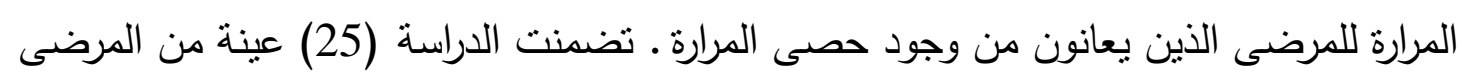
الذين يعانون من الإصابة بحصى المرارة والذين تم تشخيص الحالة لديهم باستخدام السونار (11) منهم مدخنين ، تتراوح أعمار المرض عى مابين (40-60) سنة، ومقارنتها مع (25) عينة

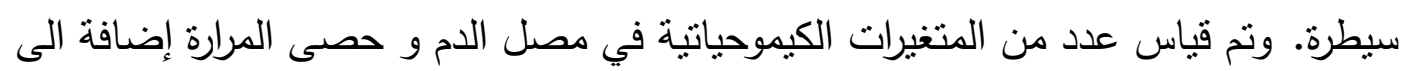

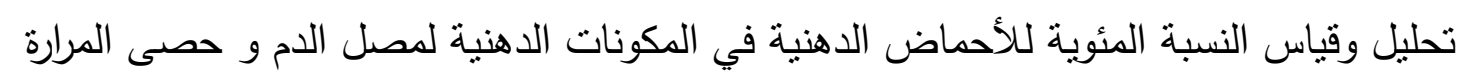
(استر الكوليستيرول، الدهون الفوسفاتية والكليسيرايد الثلاثي) وذللك باستخدام تقنية كروما توكرافيا الطبقة الرقيقة بعد ذلك تم إعادة أسترة الأحماض الدهنية وقياس النسبة المئوية لها باستخدام

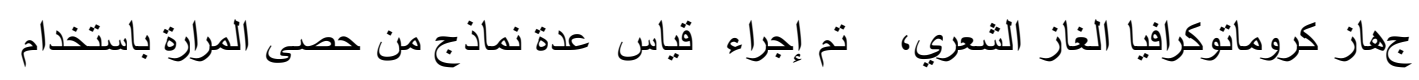

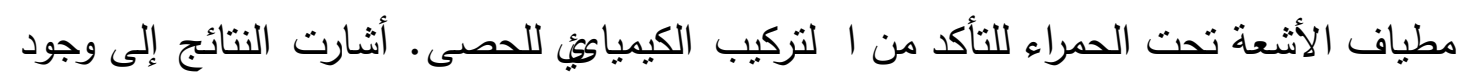

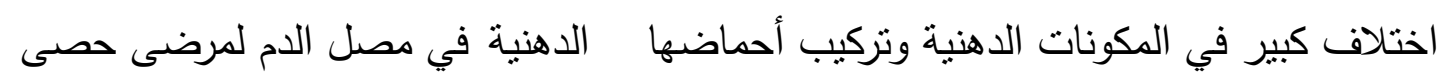

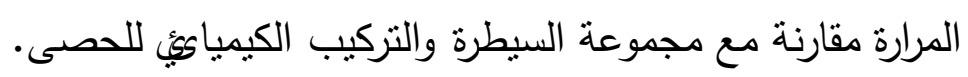

\section{ABSTRACT}

This study was designed to compare the level of lipid fractions and percentage of fatty acids in serum and gallstones in patients with gallstone, the study include 25 gallstone patients who were diagnosed by ultrasonography, the age is between (40-60) year and compared with (25) normal subject with same age were collected as control and measurement of a number of biochemical parameters in serum and gallstone, as well as analysis and measurement of percentage of fatty acids in the fatty 
component of serum and gallstone (cholesterol ester, phospholipids and triglyceride) by using thin layer chromatography (TLC) and then reesterfication fatty acids and measurement percentage of fatty acids using capillary gas chromatography (CGC). also the study include chemical composition of gallstones by using Fourier transform infrared (FTIR). the result of this study show that there is a significant differences in the level of studied biochemical parameter and fatty acids percentage in gallstone patients compared with the control group.

\section{INTRODUKCTION}

Gallstones form when liquid stored in the gall bladder hardens into pieces of stone-like material. The liquid, called bile, is used to help the body digest fats. Bile is made in the liver, then stored in the gall bladder until the body needs to digest fat. At that time, the gall bladder contracts and pushes the bile into a tube-called a duct-that carries it to the small intestine, where it helps with digestion. Bile contains water, cholesterol, fatty acids, fats, bile salts, and bilirubin. Bile salts break up fat, and bilirubin gives bile and stool a brownish color. If the liquid bile contains too much cholesterol, bile salts, or bilirubin, it can harden into stones. The two types of gallstones are cholesterol stones and pigment stones. Cholesterol stones are usually yellow-green and are made primarily of hardened cholesterol. They account for about 80 percent of gallstones. Pigment stones are small, dark stones made of bilirubin. Gallstones can be as small as a grain of sand or as large as a golf ball. The gallbladder can develop just one large stone, hundreds of tiny stones, or almost any combination (1). The process of gallstone formation is referred to as cholelithiasis. It is generally a slow process, and usually causes no pain or other symptoms. Patients can have a mixture of the two types(2). The effects of dietary factors are less conclusive; additional studies are therefore necessary to clarify their relevance in the pathogenesis of gallstone disease. Recent discoveries of the role of orphan nuclear receptors in the regulation of fatty acid and hepatic cholesterol metabolism and excretion open new perspectives for a better understanding of the role of dietary constituents on cholesterol gallstone formation(3).

\section{Samples collection:-}

\section{Materials and Methods}

In this study the blood samples were collected from gallstone patients after fasting period for (10-12) hours and (5)ml of blood from each subject was collected and serum was separated from it and then divided in to two parts: $1^{\text {st }}$ part measurement of the following parameters total cholesterol(TC), high density lipoprotein cholesterol(HDL-C), 
triglyceride (TG), low density lipoprotein cholesterol (LDL-C) by enzymatic methods using kites $(4,5)$, very low lipoprotein cholesterol(VLDL-C) was measurement theoretical(6), and phospholipids(PL) by colorimetric method (7). the $2^{\text {nd }}$ part was stored at $(-18)^{\circ} \mathrm{c}$ until measurement of fatty acids.

2. Extraction and Separation of serum main lipids:

Serum samples were treated with methanol and chloroform to extract lipids(8), lipids extract was separated into three parts cholesterol ester (CE), triglyceride(TG), phospholipids(PL) using thin layer chromatography (TLC). (9)

\section{Transmethylation of fatty acids:}

In this study analysis and esterfication of fatty acids by using trifloro boron $\left(\mathrm{BF}_{3}\right)$ in Methanol(16\%)(10).

\section{Measurmeant of percentage of fatty acids:}

Measurement of fatty acids in the three lipid fractions was performed by Capillary Gas Chromatography (CGC) Shimadzo 2010, column type TR-WAX, and length 30m, in industry center (Syria).

\section{Analysis of gallstones:}

Gallstone from (25) patients cholelithiasis (11)smokers were collected from males in Ibn-Sena hospital as verified by ultrasonography, the stone were powdered in a pestle and mortar and dissolved in different solvents depending upon the type of chemical constituent to be analyzed. To determine total cholesterol(TC), (50) $\mathrm{mg}$ of stone powder was dissolved in (3)ml of chloroform and was kept in boiling water bath for (2)min and then stone solution was used for determination this parameters by enzymic method (4). and to determine triglyceride (TG), (50)mg of stone powder was dissolved in (3)ml of 1N HCL (25) and final volume to (10)ml with distilled water and tube was kept in boiling water bath for (1)h and then determination (TG) by enzymic method (5). to determine phospholipids (50) $\mathrm{mg}$ of stone powder was dissolved in (15)ml of chloroform and methanol (2:1)containing $1 \mathrm{~N}$ HCL and then determination (PL) by colorimetric method (7). to determination the percentage of fatty acids in three parts of gallstone lipids (CE,PL,TG), (50) $\mathrm{mg}$ of stone powder dissolved in(12) $\mathrm{ml}$ of chloroform and methanol (4:2) and then extraction lipids and separated into three parts (CE,PL,TG) by TLC and then analysis and measurement percentage of fatty acids by methods using in blood serum. $(8,9,10)$.

6- Analysis gallstone by fourier transform infrared (FTIR):

This study include chemical analyses of gallstones and standard sample of cholesterol by FTIR to comparison with two structure (11).

7. Statistical analysis: 
Results were analyzed statistically for biochemical parameters and the percentage of fatty acids using $\boldsymbol{t}$-test, $\boldsymbol{P}<0.05$ was considered statistically significant (12).

\section{1- Lipid fractions:}

\section{Results and Dissociation}

The results showed that a significant increase in total cholesterol (TC) in gallstone patients compared with that of control group as indicated in table (1) this increase may be due to increase in bile saturation that results from an increase in the biliary secretion of cholesterol and higher synthesis rate of cholesterol because of insulin resistance $(13,14)$. and the results showed that a significant decrease in (HDL-C) in gallstone patients comparison with control group as show in table (1) the cause of that may be due to close relationship to the elevated activity of plasma CETP (cholesterol ester transfer protein) which promotes the lipoprotein cholesterol of HDL to be transfered to other lipoprotein in gallstone patients (15). on the other hand, the results showed that a significant increase in (LDL-C) may be due to defect in hepatic receptor (Apo B100) which plays an important role in increasing (LDL-C) through decreasing transport of (LDL-C) to hepatic tissue(16). But the results of (TG) and (VLDL-C) in gallstone patients showed unsignificant results compared with control group as show in table (1). wherease the results showed that a significant increase in (PL) this increases may be due to action of hepatic lipases which lead to abnormality metabolism of lipids specially phospholipids (17) and may cause of smoking which the import factor of increase (PL) in serum (18).

Table(1): Serum lipids from gallstone patients and control subjects

\begin{tabular}{|c|c|c|c|}
\hline $\begin{array}{c}\text { Lipid fraction } \\
\mathrm{mmol} / \mathrm{l}\end{array}$ & $\begin{array}{c}\text { Gallstone patients } \\
25\end{array}$ & $\begin{array}{c}\text { Control } \\
25\end{array}$ & P value \\
\hline TC & $5.67 \pm 0.37$ & $4.23 \pm 0.23$ & $<0.001$ \\
\hline HDL-C & $0.97 \pm 0.23$ & $1.35 \pm 0.16$ & $<0.001$ \\
\hline LDL-C & $5.10 \pm 0.65$ & $4.22 \pm 0.31$ & $<0.001$ \\
\hline TG & $2.00 \pm 0.87$ & $1.85 \pm 0.23$ & 0.1 \\
\hline VLDL-C & $0.9 \pm 0.08$ & $0.83 \pm 0.03$ & 0.12 \\
\hline PL & $175 \pm 14.54$ & $154 \pm 11.87$ & $<0.05$ \\
\hline
\end{tabular}

Values:Mean \pm SD

\section{2- Percentage of fatty acids:}

The percentage of fatty acids was measured by using (CGC) through comparison of results with standard sample composed of (12) fatty acids, as indicated in fig(1): from the result analysis of standard sample of fatty acids and table (2)demonstrated a retention time (Rt) of these standard fatty acids. 


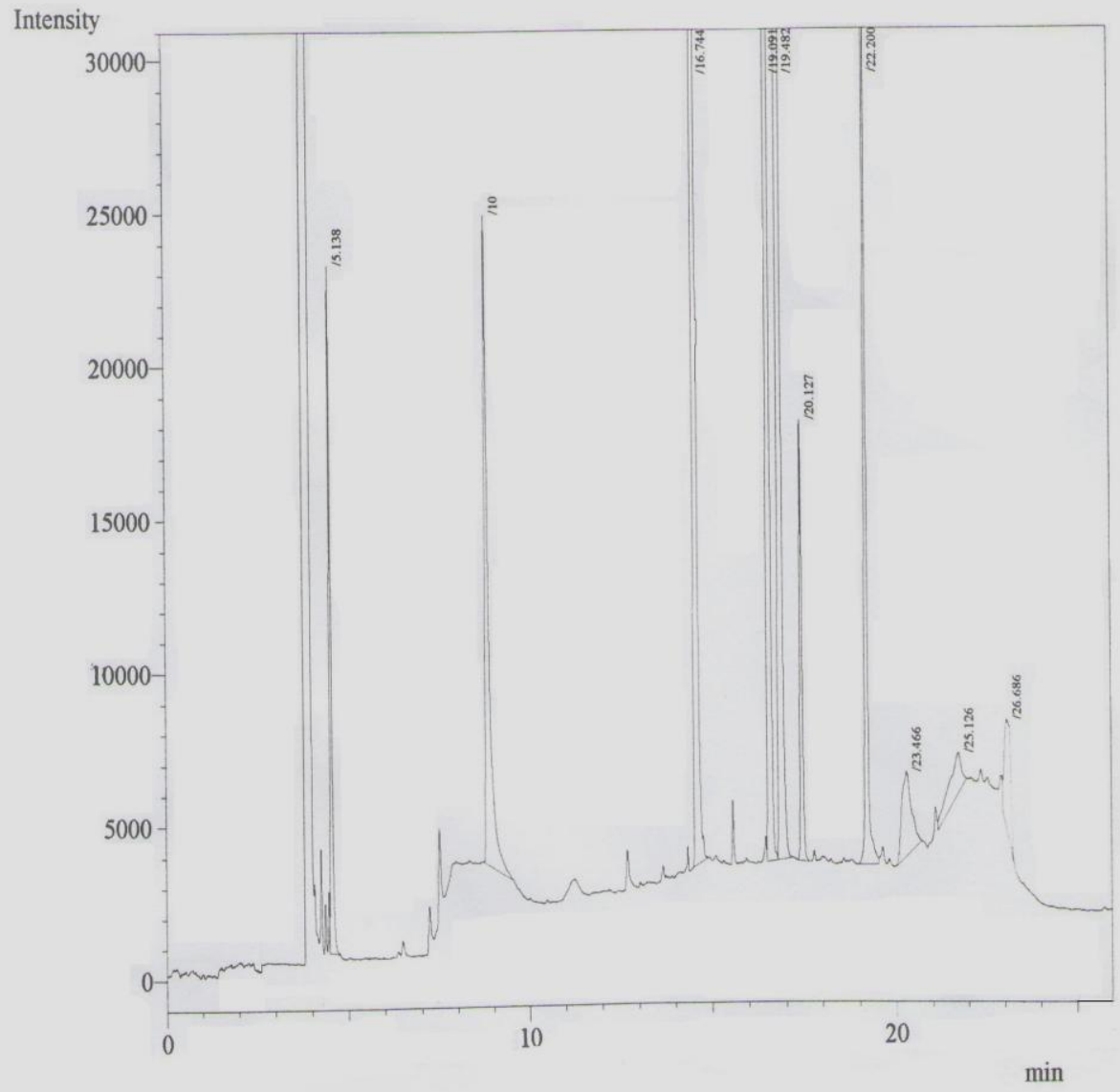

Figure (1): The CGC chart of (12) standard fatty acids 
Table (2): standard fatty acids

\begin{tabular}{|c|c|c|}
\hline Standard fatty acids & Symbol & Retention time(min) \\
\hline Capric acid & C10:0 & 4.900 \\
\hline Lauric acid & C12:0 & 5.138 \\
\hline Myristic acid & C14:0 & 8.500 \\
\hline Palmitic acid & C16:0 & 10.08 \\
\hline Palmitoleic acid & C16:1 & 16.74 \\
\hline Stearic acid & C18:0 & 19.09 \\
\hline Oleic acid & C18:1 & 19.48 \\
\hline Linoleic acid & C18:2 & 20.12 \\
\hline Linolenic acid & C18:3 & 22.20 \\
\hline Arachidonic acid & C20:4 & 23.46 \\
\hline Eicosapentaenoic acid & C20:5 & 25.12 \\
\hline Docosahexaenoic acid & C22:6 & 26.68 \\
\hline
\end{tabular}

\section{1- Percentage of fatty acids in (CE) part:}

The results showed that a significant increases in percentage of total saturated fatty acids (SFA) in gallstone patient in comparison with control group,as show in table (3), this increasing may be due to abnormality in metabolism of fatty acids in gallstone patients (19). also a significant decrease in percentage of total monounsaturated fatty acids (MUFA) and a significant increase in percentage of total polyunsaturated fatty acids (PUFA) in this parts, this increasing may be due to insulin resistance in gallstone patients which leads to a big defect in enzymes action which leading to defect in percentage of unsaturated fatty acids (14).

\section{2- Percentage of fatty acids in (PL) part:}

The results showed that a significant decrease in percentage of total (SFA), on the other hand a significant increase in percentage of total (MUFA) and (PUFA) in gallstone patients in comparison with control group, as show in table (3), this decreasing or increasing may be due to defect in action of desaturation enzyme $(\Delta 9)$ desaturase and elongation enzymes $(\Delta 6),(\Delta 5)$ in gallstone patients $(20)$.

\section{3- Percentage of fatty acids in (TG) part:}

The results showed that a significant increase in percentage of total (SFA) and total (MUFA), on the other hand a significant decrease in percentage of total (PUFA) in gallstone patients in compared with that of control group, as shown in table (3), this may be due to some type of food(butter fat and hydrogenate vegetable oils) which leads to increase the risk factor of gallstone disease such as trans-fatty acid (21), or may be due to transport (Acetyl-CoA) from different metabolism pathway to pathway causes anabolism of fatty acids (22). 
Table(3): Percentage of fatty acids composition of CE,PL,TG in serum gallstone patients and control group

\begin{tabular}{|c|c|c|c|c|c|c|}
\hline \multirow{2}{*}{ Fatty acid } & \multicolumn{2}{|c|}{ CE } & \multicolumn{2}{c|}{ PL } & \multicolumn{2}{c|}{ TG } \\
\cline { 2 - 7 } & control & gallstone & control & gallstone & control & gallstone \\
\hline $\mathrm{n}$ & 10 & 10 & 10 & 10 & 10 & 10 \\
\hline SFA & & & & & & \\
\hline $10: 0$ & $1.0 \pm 0.13$ & $0.70 \pm 0.05$ & $0.09 \pm 0.01$ & $0.69 \pm 0.08$ & $0.10 \pm 0.04$ & $0.3 \pm 0.10$ \\
\hline $12: 0$ & $1.3 \pm 0.23$ & $1.62 \pm 0.22$ & $1.5 \pm 0.31$ & $1.75 \pm 0.09$ & $2.00 \pm 0.30$ & $6.0 \pm 0.15^{*}$ \\
\hline $14: 0$ & $0.56 \pm 0.10$ & $1.36 \pm 0.30$ & $0.38 \pm 0.1$ & $2.95 \pm 0.18^{*}$ & $4.0 \pm 0.65$ & $5.24 \pm 0.38$ \\
\hline $16: 0$ & $6.00 \pm 1.52$ & $3.80 \pm 1.21^{*}$ & $10.25 \pm 2.8$ & $2.43 \pm 0.89^{*}$ & $25.0 \pm 2.60$ & $24.0 \pm 3.34$ \\
\hline $18: 0$ & $3.00 \pm 0.47$ & $10.52 \pm 2.21^{*}$ & $10.01 \pm 1.3$ & $11.75 \pm 1.87$ & $5.25 \pm 1.24$ & $7.25 \pm 0.9^{*}$ \\
\hline Total & $11.86 \pm 2.45$ & $18.00 \pm 3.99^{*}$ & $22.23 \pm 4.5$ & $19.57 \pm 3.11^{*}$ & $36.35 \pm 4.83$ & $42.8 \pm 4.9^{*}$ \\
\hline MUFA & & & & & & \\
\hline $16: 1$ & $1.70 \pm 1.20$ & $2.23 \pm 0.87$ & $2.30 \pm 0.7$ & $5.6 \pm 0.87 *$ & $3.50 \pm 0.35$ & $7.28 \pm 1.2^{*}$ \\
\hline $18: 1$ & $18.0 \pm 2.54$ & $15.0 \pm 2.65^{*}$ & $8.30 \pm 1.44$ & $9.26 \pm 2.11$ & $20.24 \pm 1.24$ & $18.9 \pm 1.8^{*}$ \\
\hline Total & $19.70 \pm 3.74$ & $17.23 \pm 3.52^{*}$ & $10.6 \pm 2.14$ & $14.86 \pm 2.98^{*}$ & $23.74 \pm 1.59$ & $26.18 \pm 3 . *$ \\
\hline PUFA & & & & & & \\
\hline $18: 2 \mathrm{n}-6$ & $20.0 \pm 2.43$ & $22.0 \pm 3.32^{*}$ & $18.78 \pm 3.2$ & $17.65 \pm 1.65$ & $18.26 \pm 2.77$ & $17.12 \pm 1.9$ \\
\hline $18: 3 \mathrm{n}-3$ & $2.30 \pm 0.44$ & $4.50 \pm 0.76^{*}$ & $2.10 \pm 0.98$ & $5.74 \pm 2.43^{*}$ & $2.85 \pm 0.67$ & $1.80 \pm .55$ \\
\hline $20: 4 \mathrm{n}-6$ & $6.80 \pm 1.77$ & $10.23 \pm 1.83^{*}$ & $10.24 \pm 3.2$ & $14.28 \pm 2.29^{*}$ & $4.85 \pm 0.55$ & $3.24 \pm .76$ \\
\hline $20: 5 \mathrm{n}-3$ & $1.56 \pm 0.5$ & $4.00 \pm 0.88^{*}$ & $2.85 \pm 0.34$ & $5.56 \pm 1.20^{*}$ & $2.90 \pm 0.54$ & $2.68 \pm .21$ \\
\hline $22: 6 \mathrm{n}-3$ & $2.38 \pm 0.91$ & $5.00 \pm 0.67^{*}$ & $2.3 \pm 0.50$ & $4.5 \pm 1.54^{*}$ & $6.65 \pm 0.88$ & $2.56 \pm 1.3^{*}$ \\
\hline Total & $33.04 \pm 6.0$ & $45.73 \pm 7.46^{*}$ & $36.27 \pm 8.2$ & $47.73 \pm 9.11^{*}$ & $35.51 \pm 5.41$ & $27.4 \pm 4.7^{*}$ \\
\hline $\mathrm{n}-3$ & $6.24 \pm 1.85$ & $13.50 \pm 2.31^{*}$ & $7.25 \pm 1.82$ & $15.8 \pm 5.17^{*}$ & $10.40 \pm 2.09$ & $10.04 \pm 2.1$ \\
\hline $\mathrm{n}-6$ & $26.8 \pm 4.20$ & $32.23 \pm 5.15^{*}$ & $29.0 \pm 6.40$ & $31.93 \pm 3.94^{*}$ & $20.11 \pm 3.32$ & $25.36 \pm 2 .^{*}$ \\
\hline Valus: & & & & &
\end{tabular}

Values: Mean \pm SD *: P value $<0.05$

\section{3- Gallstone analysis:}

The results of this study showed that the biliary calculi collected from 25 gallstone patients were cholesterol stones depending of colors (yellow-green) and the FTAR analysis, as show in fig (2), and the lipids quantitative analysis of the 25 gallstones are expressed as $\mathrm{mg} / \mathrm{gm}$ of stone powder in table (4).

Total cholesterol (TC): the results showed that total (TC) was higher than that other types of gallstones this may be due to formation of gallstone, when the concentration of cholesterol exceeded that which can held in mixed micellar solution with bile acids and phospholipids, super saturation of cholesterol due to abnormal production of bile from liver (23).

Triglycerides (TG): the results showed that the (TG) content was highest,the causes of that may due to more deposition of calcium salts of cholesterol and ester of fatty acids in cholesterol stone (24).

Phospholipids (PL): the results showed that the (PL) content was highest, the causes of that may due to accumulation of phospholipids along with cholesterol during cholesterol stone formation and the accumulation of 
(PL) could either be due to their enhanced biosynthesis or decreased utilization(25).

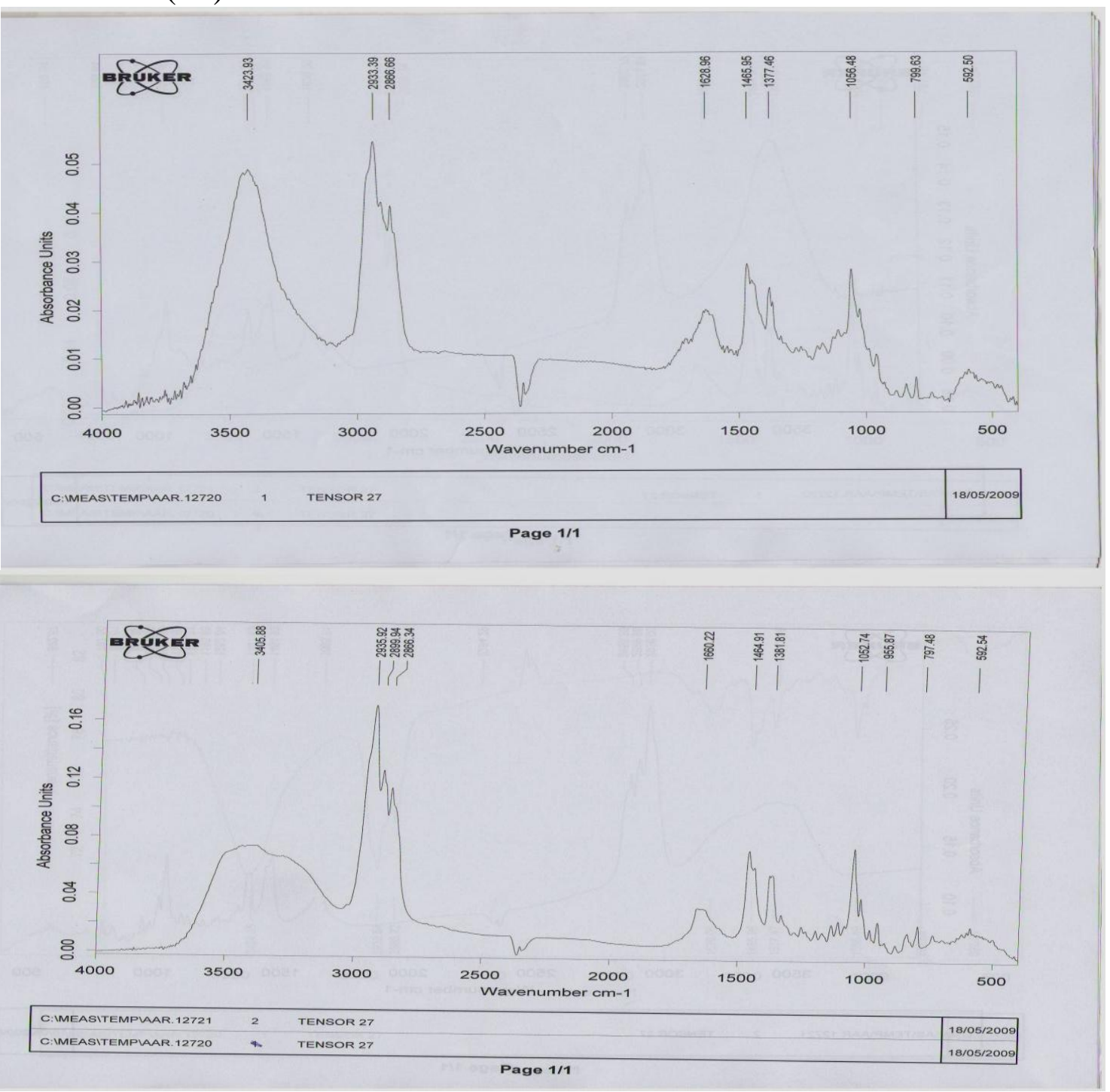

Figure(2): FTAR analysis.1-cholesterol standard.2-gallstone

Table(4): lipids analysis of gallstones expressed as $\mathrm{mg} / \mathrm{gm}$

\begin{tabular}{|c|c|}
\hline Lipids fractions $\mathrm{mg} / \mathrm{gm}$ & Gallstones 25 \\
\hline TC & $525.43 \pm 21.32$ \\
\hline TG & $84.46 \pm 9.32$ \\
\hline PL & $20.78 \pm 2.34$ \\
\hline
\end{tabular}

Values:Mean $\pm \mathrm{SD}$

Fatty acids composition:

The results showed that the percentage of fatty acids was different between three parts of lipids gallstone as shown in table (5), this difference may be due to type of food intake (26).also the results showed that the percentage of $(n-6 / n-3)$ was higher which referred to the risk factor of development gallstone disease and increase risk for developing 
ischemic heart disease (27).on the other hand the results showed that increase in percentage of total unsaturated fatty acids (MUFA and PUFA) in gallstone this might be due to interaction between excessive cholesterol and fatty acids (25),or the cause may be due to action of phospholipase A and phospholipase A2 which coming from pancreatic reflux and these enzymes mainly catalyzes the sn-2 bond of unsaturated fatty acids (20).

Table(5): Percentage of fatty acids composition of CE,PL,TG in gallstones

\begin{tabular}{|c|c|c|c|}
\hline Fatty acids & CE part (10) & PL part (10) & TG (10) \\
\hline \multicolumn{4}{|l|}{ SFA } \\
\hline 10:0 & $0.15 \pm 0.04$ & $0.68 \pm 0.12$ & $0.20 \pm 0.01$ \\
\hline $12: 0$ & $0.78 \pm 0.15$ & $1.16 \pm 0.22$ & $0.43 \pm 0.08$ \\
\hline $14: 0$ & $1.97 \pm 0.43$ & $4.04 \pm 1.33$ & $1.39 \pm 0.11$ \\
\hline 16:0 & $5.40 \pm 1.23$ & $10.7 \pm 2.11$ & $3.46 \pm 0.98$ \\
\hline 18:0 & $10.0 \pm 2.34$ & $14.1 \pm 2.54$ & $8.09 \pm 1.22$ \\
\hline Total & $18.3 \pm 4.19$ & $30.68 \pm 6.32$ & $13.57 \pm 2.4$ \\
\hline \multicolumn{4}{|l|}{ MUFA } \\
\hline $16: 1$ & $3.60 \pm 0.45$ & $9.0 \pm 2.11$ & $6.33 \pm 1.89$ \\
\hline $18: 1$ & $5.20 \pm 1.12$ & $4.25 \pm 0.87$ & $8.50 \pm 2.13$ \\
\hline Total & $8.8 \pm 1.57$ & $13.25 \pm 2.98$ & $14.83 \pm 4.0$ \\
\hline \multicolumn{4}{|l|}{ PUFA } \\
\hline $18: 2 n-6$ & $16.0 \pm 3.22$ & $14.2 \pm 2.33$ & $20.0 \pm 3.67$ \\
\hline $18: 3 n-3$ & $6.0 \pm 1.11$ & $9.74 \pm 1.89$ & $8.33 \pm 1.83$ \\
\hline $20: 4 n-6$ & $13.46 \pm 3.24$ & $8.21 \pm 0.34$ & $16.0 \pm 4.21$ \\
\hline $20: 5 n-3$ & $1.19 \pm 0.12$ & $3.67 \pm 0.22$ & $5.65 \pm 0.93$ \\
\hline $22: 6 n-3$ & $1.87 \pm 0.44$ & $3.20 \pm 0.94$ & $4.24 \pm 0.95$ \\
\hline Total & $38.52 \pm 8.13$ & $39.02 \pm 5.72$ & $54.22 \pm 11.59$ \\
\hline$n-6$ & $29.46 \pm 6.46$ & $22.41 \pm 2.67$ & $36.0 \pm 788$ \\
\hline$n-3$ & $9.06 \pm 1.67$ & $16.61 \pm 3.0$ & $18.22 \pm 3.71$ \\
\hline
\end{tabular}

Values $=$ mean \pm S.D 
Analysis Date: 19/03/2009

User Name Unknown : Admin

Sample Name : oil

Sample ID $\quad$ : fat_106

Sample Type : Unknown

Data Name $\quad:$ C:IGCsolutionlDatalProjectllfaty $\quad$ :.ged

Method Name $\quad:$ C:IGCsolutionWDatalProject11OIl.gcm

Sample Information

Chromatogram - Channel 1 oil C:IGCsolution\DatalProjectllfaty\&ged

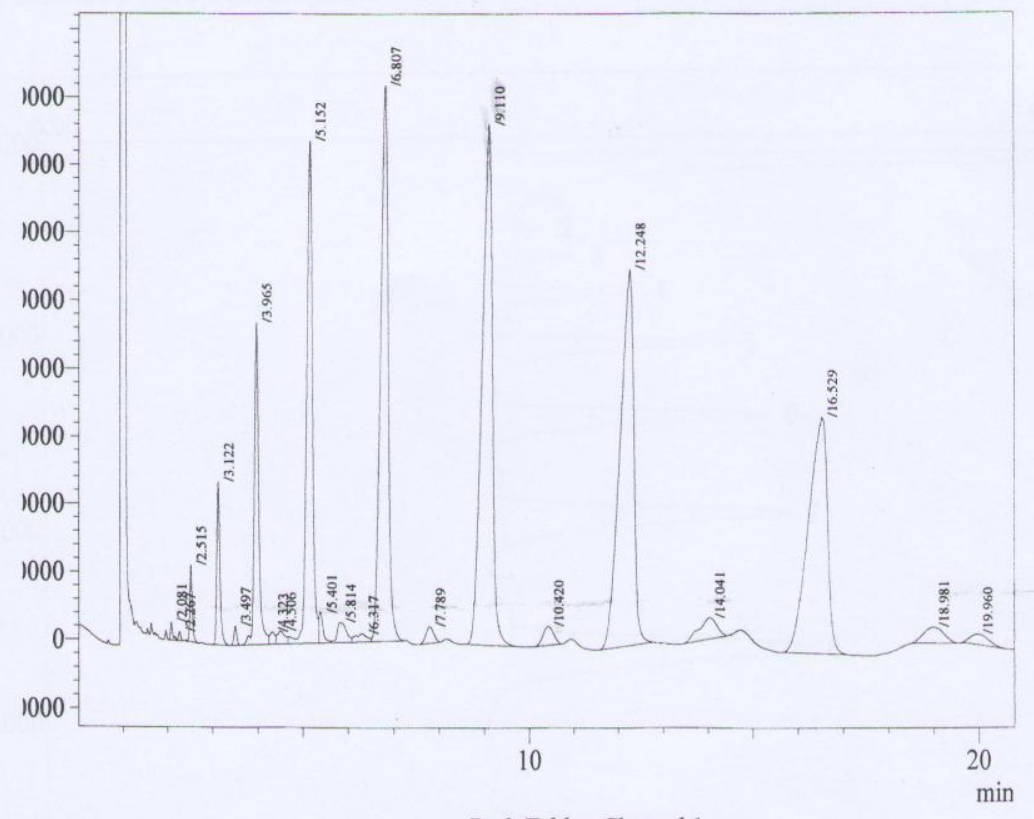

\begin{tabular}{rrrrrl} 
& & \multicolumn{5}{c}{ Peak Table - Channel l } \\
Peak\# & Ret. Time & Area & Area\% & Height Mark Cmpd Name \\
1 & 2.081 & 46376 & 0.1562 & 12226 & \\
2 & 2.267 & 22402 & 0.0755 & 6496 & $\mathrm{~V}$ \\
3 & 2.515 & 206969 & 0.6972 & 53664 & \\
4 & 3.122 & 583314 & 1.9649 & 117011 & \\
5 & 3.497 & 61125 & 0.2059 & 13804 & \\
6 & 3.965 & 1625832 & 5.4767 & 233238 & \\
7 & 4.323 & 67021 & 0.2258 & 8898 & $\mathrm{~V}$ \\
8 & 4.506 & 111518 & 0.3757 & 9288 & $\mathrm{~V}$ \\
9 & 5.152 & 3264744 & 10.9975 & 365863 & $\mathrm{~V}$ \\
10 & 5.401 & 137853 & 0.4644 & 22802 & $\mathrm{~V}$ \\
11 & 5.814 & 203548 & 0.6857 & 14754 & $\mathrm{~V}$ \\
12 & 6.317 & 111550 & 0.3758 & 6051 & $\mathrm{~V}$ \\
13 & 6.807 & 4754858 & 16.0170 & 408429 & $\mathrm{~V}$ \\
14 & 7.789 & 145472 & 0.4900 & 12067 & \\
15 & 9.110 & 6124438 & 20.6305 & 382156 & \\
16 & 10.420 & 228976 & 0.7713 & 13812 & \\
17 & 12.248 & 5905082 & 19.8916 & 275259 & \\
18 & 14.041 & 435709 & 1.4677 & 15458 & \\
19 & 16.529 & 5082772 & 17.1216 & 174172 & \\
20 & 18.981 & 355901 & 1.1989 & 11676 & \\
21 & 19.960 & 210800 & 0.7101 & 7468 & \\
Total & & 29686260 & 100.0000 & 2164593 &
\end{tabular}

Figure (3): The CGC chart of fatty acids in CE part of gallstone References 
1) Steve Z. Penny S. Gallstones and Gallbladder. foundation for better health care.99. (2009)

2) Shaffer A. Gallstones disease. best. pract. Res. clin. gastronenterol; 20: 981-996. (2006)

3) Cuevas A. Juan M. and Maria S. Diet as a risk factor for cholesterol gallstone disease. J. Am. Nutr. 23:187-196.(2004)

4) Burtis C, Ashwood E. Tiets Text Book of Clinical Chemistry. $3^{r}$ ed. W. B. Saunders Com.:pp110-115. (1999)

5) Kosnor G. M. Enzymatic determination cholesterol in HDL fraction. Clin.Chem.; 22:665-670. (1976)

6) Michael L, Edward P, Larry S. Clinical Chemistry. $5^{\text {th }}$ Williams \&Wilkins.; pp.288-292. (2005)

7) Tietz N. Text Book of Clinical Biochemistry. W. B. Saunders Com. Philadelphia,USA;135-140.(1986)

8) Folsom A. Ma J. Eckteidt J. Relation between plasma phospholipids. Metabolism; 45:223-228.(1996)

9) Murray R. Gramner D. Rodweu V. Harpers Biochemistry. $25^{\text {th }}$ ed. Appleton and Lange; p.155-170.(2000)

10) Ma J. Shahar E. Plasma fatty acids composition in middle-age adults. Am.J.Clin. Nutr.; 62:564-571. (2005)

11) Naseem A. Fateh D. and Mohammad H. Pak. J. Med. Sci.; 23:546550. (2007)

12) Leonard T. Kathleen R. The ways and means of statistics. Harcourt Brace Jovanovich.; pp.490-495. (1979)

13) Liu CM, Tung TH, Liu JH, Lee WL, Chou P. A community-based epidemiologic study on gallstone disease among type 2 diabetics in Kinmen, Taiwan. Dig Dis.; 22:87-91. (2004)

14) Scragg R. and Oliver J. Plasma lipids and insulin in gallstone disease. Br. Med. J. 289:521-525. (1984)

15) Juvonen $T$. Lajunen $H$. Polymorphisms CETP gene loci in patients with gallstone. J. lipids Res. 36:804-812.(1995)

16) Karen K. Kunt B. and Jan S. Transvascular LDL-C transport in patients with NIDDM. Arteriosclerosis; 22:1168. (2002)

17) Murray R. Gramner D and Rodweu W. Harper's Biochemistry $25^{\text {th }}$ ed. Appleton and Lange, USA: 150-160.(1996) 
18) Al-Tamer Y. and Al-Juraisy A. Lipids component and fatty acid composition of Iraqi subjects who smoke and consume dairy products. Nurt. Metab. Cardiovasc. Dis.14:94-96.(2004)

19) Mohr G. Kritz D. and Barret E. Plasma lipids and gallstone disease. Am. J.Epidemiol.,134:78-85.(1991)

20) Shuo D. Kazuhisa U. and Ying F. The role and mechanism of fatty acids in gallstones. Hepatobiliary pancreat Dis. Int.4:399-402.(2007)

21) Cate S. and Helsu D. Trans fatty acids increase the risk factor of gallstone disease. General Health News. (2005)

22) Vessby B., Boberg M. and Andersson A. Desaturation and elongation of fatty acids and insulin action. Annals. of New York Academy of Sci., 967: 183-195. (2002)

23) Pundir C. Chandran P. and Garg P. Chemical analysis of biliary calculi in Haryana. Ind.J.Surg; 63:370-373. (2001)

24) Moore $W$. The role of calcium in the pathogeneses of gallstones. Hepatology; 4:228-243. (1994)

25) Chandran P. Grag P.An extended chemical analysis of gallstone. Ind. J. Clin.Bio.; 22:145-150. (2007)

26) Mohammed A. Variations in dietary intake between newly diagnosed gallstone patients and control. Pakistan J. Nutr.; 4:1-7. (2005)

27) Daniel M. Kuba D. and Lara B. strong association between gallstones and cardiovascular disease. Amer. J. Castoro.; 100:827830. (2005) 